\title{
Concealed endophytic nematode management in sunflower using plant- based soil amendments
}

\author{
Sarir Ahmad ${ }^{1 *}$, Ayesha Hameed ${ }^{2}$, Ahmad-Ur-Rahman Saljoqi ${ }^{1}$, Bibi \\ Safia $^{3}$ and Asad Ali ${ }^{2}$
}

1. Plant Protection Department, The University Of Agriculture Peshawar-Pakistan

2. Department of Botany, Abdul Wali Khan University Mardan-Pakistan

3. Department of Zoology, Islamia College University Peshawar-Pakistan

*Corresponding author's email: sarirplants@gmail.com

Citation

Sarir Ahmad, Ayesha Hameed, Ahmad-Ur-Rahman Saljoqi, Bibi Safia and Asad Ali. Concealed endophytic nematode management in sunflower using plant-based soil amendments. Pure and Applied Biology. Vol. 9, Issue 3, pp1763-1773. http://dx.doi.org/10.19045/bspab.2020.90187

\begin{tabular}{llll}
\hline \hline Received: 05/01/2020 & Revised: 22/03/2020 & Accepted: 17/04/2020 & Online First: 18/04/2020 \\
\hline \hline
\end{tabular}

\section{Abstract}

The current in-planta research work was carried out for the management of root-knot nematode (Meloidogyne incognita) in sunflower (Helianthus annuus) cv. Peshawar.93 through naturally occurring nematicides during spring, 2018. Experiment included two plant-based essential oils (neem oil and castor oil), two plant extracts (garlic and ginger), and furadon (positive check). In contrast, check (negative) received only pure distal water $\left(\mathrm{H}_{2} \mathrm{O}\right)$. Treatments were laid out in CR (completely randomized) design having five replications. We inoculated 50 Juvenile's (J2s) and 200 eggs of the root-knot nematode to the sunflower root system. Application of plant extracts caused a significant decline in the number of galls, galling index, egg masses and $\mathbf{J} 2$ population on sunflower plant and promoted plant growth parameters under greenhouse conditions. Least number of egg masses $(0.80)$ were found in plant treated with neem oil followed by furadon $(0.83)$. Neem oil significantly reduced $1.46 \mathrm{~J} 2 \mathrm{~s}$, followed by furadon (1.96). Plant Growth parameters such as shoot length $(28.3 \mathrm{~cm})$, root length $(13.4 \mathrm{~cm})$, root weight $(3.15 \mathrm{gm})$, fresh $(4.36 \mathrm{gm})$ and dry shoot weight $(3.2 \mathrm{gm})$ and dry root weight $(1.6 \mathrm{gm})$ were increased significantly by using neem oil. All the treatments significantly increased the plant growth parameters over check negative. The total chlorophyll content of the plants had reduced after the inoculation of the nematode as compared with the pre nematode inoculation. The present study suggests that neem oil has strong nematicidal effects and can be utilized effectively in an integrated pest management program against root-knot nematodes in sunflower.

Keywords: Botanicals; Neem oil; Root-Knot nematode; Soil amendments; Sunflower

Introduction

Sunflower (Helianthus annuus L.), a member of the Compositae family, is a vital oilseed crop worldwide, yielding approximately $45-$ $50 \%$ oil (dehulled seed mass basis). In Pakistan, producers consider sunflower as a non-conventional oilseed crop and are generally grown in two seasons, spring and summer. In wide range climatic conditions of Pakistan, sunflower crop fits well in the local intercropping systems and could be successfully grown in spring and fall, thus 
yielding two crops in 1 year [1]. A huge potential exists to increase the domestic production of sunflower in Pakistan. Recently, agriculturists are making substantial efforts to raise the production of this crop.

Numerous causes, such as occasional adverse abiotic stresses and biotic factors like diseases and insect pests, are the reasons for the lower production of sunflowers. Sunflower in different growth stages is attacked by several diseases, which significantly declining its overall production as well as qualitative losses significantly under optimum temperature and environment [2]. Sunflower is under attack by several pathogens including Nematodes, Bacteria, and Fungi which reduces yield and quality [3].

Amongst nematode, the root-knot nematode (RKN) species like Meloidogyne incognita pose a significant threat to sunflower production. RKN infection in sunflower is becoming a great one of the most severe cataclysms for better and higher yields of sunflower [4]. It is an estimate that RKN causes almost $16.44 \%$ of production losses to sunflowers [4]. RKN are polyphagous and infect over 5,500 host plants [5]. They are in the top five pathogens which causes disease in several plants $[6,7]$

In the Khyber Pakhtunkhwa province, the problem of RKNs is more severe, particularly in the Malakand division [8] as the area is more suitable for vegetation production and its enemies. Malakand divisions provide main vegetables and oilseed crops to the plane of Peshawar and adjacent cities throughout the year and, more particularly, in the winter season. However, the nematodes are well adapted to the prevailing environmental and soil conditions of Malakand divisions because viable eggs of the pathogen survive in the ground for long periods.
Furthermore, due to sandy loam soil and short life cycle of six to eight weeks, the RKN populations gradually built up in these areas in the presence of a suitable host [9]. Nematodes control is challenging because these plant parasites mostly attack underground parts of plants resulting in weak growth and less production. Above-ground symptoms are general and non-specific. The disease generally appears as clearly defined patches in the field [10]. Below-ground symptoms include galling on roots. Galls induced by RKN consist of hypertrophied cortical cells surrounding the nematodes. Lumps or galls, ranging in size from 1 to 10 $\mathrm{mm}$ in diameter, develop all over the roots. In severe infestations, heavily galled roots may rot away, leaving a weak root system with a few large galls. Mature female nematodes lay hundreds of eggs in a gelatinous matrix/egg masses on the root surface, and these eggs hatch in warm, moist soil to continue the life cycle. Continued infection of galled tissue by second and later generations of nematodes cause the formation of large galls on roots. The length of the life cycle is temperaturedependent and varies from 4 to 6 weeks in summer to 10 to 15 weeks in winter. RKN species differ in the number of generations they can produce per year; this number varies according to species and food availability. Usually, there are many generations per year, but in some species (e.g., Meloidogyne naasi), there is only one generation [11].

Keeping in view, the concealed nature of the RKN, researchers are working on finding the best non-toxic approaches for the management of RKN. Consequently, several groups of researchers are looking for nematicidal compounds. Numerous plant species, representing 57 families, have been found to contain compounds with nematicidal properties [12]. These naturally occurring phytochemicals are biologically active plant compounds and have the potential to inhibit plant diseases. The most 
important of these phytochemicals are alkaloids, tannins, flavonoids, and phenolic compounds [13]. Except for a few, many of these phytochemicals are safer to the environment or humans than traditional chemical nematicides [12]. Therefore, this research was initiated to investigate the nematicidal properties of the selected plants to achieve the following objectives; 1) to study the efficacy of plants extracts and essential oils against root-knot nematode and 2) the effect of plant growth parameters after the application plant extracts and essential oils.

Table 1. List of treatments used in Screen House experiment against Meloidogyne incognita

\begin{tabular}{|c|c|c|c|}
\hline S. No. & Treatment & Type & Dose \\
\hline 1 & Neem oil & Plant-Based oil & -do- \\
\hline 2 & Castor oil & -do- & -do- \\
\hline 3 & Ginger extract & -do- & -do- \\
\hline 4 & Garlic extract & -do- & Standard (1g per pot) \\
\hline 5 & Furadon & Insecticide & - \\
\hline 6 & Check & Simple Distal water & \\
\hline
\end{tabular}

\section{Plant transplantations}

We purchased seeds of sunflower (cv. Peshawar.93) from Peshawar local market (Ghur Mandi). Each pot was (earthen, 1000g soil capacity) sown with three seeds. Later thinning was done, and the only plant was left. After two weeks, they were inoculated with 200 eggs and $50 \mathrm{~J} 2 \mathrm{~s}$ (24 hours old) of nematodes as a soil drench method at aseptic conditions via micropipette by making 3-5 holes around the plant [14].

\section{Nematode culture and extraction}

Field of Dargai (Malakand Division) Khyber Pakhtunkhwa was visited for the collection of nematode culture. We uprooted roots of tomato (cv. Riogrande) having galls, these roots containing soil were tagged and put into the polythene bag. Samples were brought to the lab and stored in the refrigerator for further use. After 24 hours, the root containing galls were cut into small pieces and put into the tray having water and muslin cloth above it.
Materials and methods

Green-house experiment

This experiment conducted at the newly developed Agriculture research screen house at Abdul Wali Khan University Mardan, Pakistan. A total of six treatments included in the investigation. Treatments were laid in CR (completely randomized) design and replicated five times. Essential oils purchased from Peshawar, Khyber Pakhtunkhwa, Pakistan local market, and Furadon purchased from a pesticide dealer in Peshawar. Treatments details mentioned in (Table 1).
Firstly, we put the roots on the muslin cloth. The J2s will settle in the water, and mud containing roots were above the muslin cloth [14]. We used another method of using a sieve of different sizes for the collection of eggs and $\mathrm{J} 2 \mathrm{~s}$ from the soil. The fieldcollected soil passed through mesh sieves size of 100 to $400(\mu \mathrm{m})$. The eggs of RKN settled in the sieve size $100(\mu \mathrm{m})$, while a speck of dirt remains in the topmost sieve size of $400(\mu \mathrm{m})$ [15]. Egg hatching was avoided by hydrogenizing the solution.

\section{Data parameters}

The inoculated plants uprooted after 60 days after the estimated completion of the lifecycle of RKN. We recorded the data on the RKN parameters like galls, galling index, egg masses per 10 gram of roots, and $\mathrm{J} 2 \mathrm{~s}$ per 10 gram of roots. The recorded RKN parameters were galls, galling index, egg masses per 10 gram of roots, and $\mathrm{J} 2 \mathrm{~s}$ per 10 gram of roots. We followed the galling index of Naz et al. [16]; this index is ranging from 
0-5 where 0 means nil gall, 1 means $1-2$ galls, 2 means 3-10 galls, 4 means 31-100 galls, and 5 indicates above 100 galls per root system. The data on plant growth parameters like shoot/root length and weight (fresh and dry), the total chlorophyll contents, recorded with the help of the digital SPAD meter (model. SPAD-502; Minolta Corp., Ramsey, N.J.).

\section{Statistics}

The data values were subjected to analysis of variance (ANOVA) procedures using statistical software STATISTIX (8.1, USA) version. The Fisher LSD test separated means at a $0.05 \%$ level of significance [17].

\section{Results}

Data in (Table 2) show the lowest number of galls per root system was found in neem oil 0.8 , followed by garlic extract and ginger extract 1.1 and furadon 1.3. However, among garlic, ginger extract, and furadon, no statistical difference was present at $P=0.05 \%$. Plants treated with castor oil showed 2.1 number of galls per root system, which is the least significant treatment among other treatments; however, it is statistically significant from check (6.1 galls per root system).

Data in (Table 3) suggest that neem oil treated plants has the least number of egg masses $(0.80)$ followed by furadon $(0.83)$ then followed by garlic extract (1.0), and ginger extract (1.06). However, these treatments showed no statistical significance difference; also, no significant difference was observed between castor oil and check as the number of egg masses in castor oil, and a check was 1.70 and 2.30, respectively. Results suggest that except for castor oil, all the treatments had a lowered amount of egg masses as compared to check.

A check has $3.03 \mathrm{~J} 2 \mathrm{~s}$ followed by castor oil 2.40 and then followed by ginger and garlic extract 2.0, respectively. Furadon treated plants have minimum J2s (1.96) and then followed by neem oil (1.46). All the treatments significantly lowered the J2 population as compared to check at $P=0.05 \%$ significance, as shown in (Table 3).

Garlic extract-treated plants showed the highest length $(30 \mathrm{~cm})$, followed by Furadon and neem oil $(28.6 \mathrm{~cm}$ and $28.3 \mathrm{~cm}$, respectively). Neem oil and furadon had no statistical difference for shoot length at a $P=0.05 \%$ level of significance. The then followed treatment is ginger extract $27.4 \mathrm{~cm}$ and then followed by check $19.3 \mathrm{~cm}$ and castor oil $20.3 \mathrm{~cm}$. All the treatments showed significant difference over check by increasing the shoot length except the castor oil, as shown in (Fig. 1).

Table 2. Application of treatments to Sunflower root system

\begin{tabular}{|c|c|c|}
\hline Treatment & Galls & Galling Index $^{\mathbf{1}}$ \\
\hline Neem Oil & $0.80^{\mathrm{D}}$ & 0 \\
\hline Castor Oil & $2.10^{\mathrm{B}}$ & 1 \\
\hline Garlic extract & $1.10^{\mathrm{C}}$ & 1 \\
\hline Furadon & $1.30^{\mathrm{C}}$ & 2 \\
\hline Check & $6.10^{\mathrm{A}}$ & \\
\hline LSD & 0.24 & \\
\hline
\end{tabular}

1. Galling index (Galling index (GI) using a $0-5$ galling scale, where $0=0$ on roots, $1=1-2,2=3-10,3=11-30,4=$ 31-100, 5 = More than 100 galls per root (Naz et al. 2015) [16].

2. Mean followed by the same letter do not differ significantly

Each Value is the mean of five replications 
Table 3. Egg masses and $\mathbf{J} 2$ population after application of treatments to Sunflower root system

\begin{tabular}{|c|c|c|}
\hline Treatment & Egg Masses per 10g of roots & J2s per 10g of roots \\
\hline Neem Oil & $0.80^{\mathrm{B}}$ & $1.46^{\mathrm{C}}$ \\
\hline Castor Oil & $1.70^{\mathrm{A}}$ & $2.40^{\mathrm{B}}$ \\
\hline Ginger Extract & $1.06^{\mathrm{B}}$ & $2.00^{\mathrm{B}}$ \\
\hline Garlic Extract & $1.00^{\mathrm{B}}$ & $2.00^{\mathrm{B}}$ \\
\hline Furadon & $0.83^{\mathrm{B}}$ & $1.96^{\mathrm{BC}}$ \\
\hline Check & $2.30^{\mathrm{A}}$ & $3.03^{\mathrm{A}}$ \\
\hline LSD & 0.58 & 0.50 \\
\hline
\end{tabular}

Result in (Fig. 2) suggests that neem oil treated plants had the highest root length $(13.4 \mathrm{~cm})$ followed by extract $9.6 \mathrm{~cm}$ and then followed by furadon and ginger extract 7.6 and $7.1 \mathrm{~cm}$, respectively. No statistical difference was present between furadon and ginger extract. Castor has lowered performance as compared to other treatments by having $5.5 \mathrm{~cm}$ root length; however, it was significant than check $(3.3 \mathrm{~cm})$.

Neem treated plants showed the highest fresh root weight $(3.15 \mathrm{gm})$, followed by check $(2.55 \mathrm{gm})$. The large galls increased the weight of plants in the check. Castor treated plants showed $2.43 \mathrm{gm}$ fresh root weight followed by garlic extract $(2.25 \mathrm{gm})$. Castor oil and garlic extract had a slight statistical difference at $P=0.05 \%$. The next accompanied treatment was furadon 1.86 and ginger extract (7.6 and 7.1gm, respectively), as shown in (Fig. 3).

Plants treated with furadon and neem oil had the highest gain in fresh shoot weight (4.4gm and $4.36 \mathrm{gm}$ respectively), followed by castor oil $(3.76 \mathrm{~g})$ and then ginger extract $(3.5 \mathrm{~g})$ and then followed by garlic extract $(3.3 \mathrm{~g})$. The check had the least weight gain in root fresh shoot weight $(3.03 \mathrm{gm})$. All the treatments showed statistical significance over a check at $\mathrm{P}=0.05 \%$, as shown in (Fig. 4).

Neem oil and furadon showed the highest dry shoot weight (3.20gm respectively), followed by garlic oil and ginger oil (2.40gm respectively) and then followed by and castor oil (2.2gm), the check had least (1.8gm) dry shoot weight. All the treatments were statistically significant over a check at a $P=0.05 \%$ level of significance, as shown in (Fig. 5).

Neem oil showed the highest dry root weight (1.6gm), castor oil, and furadon followed next ((1.54g and $1.50 \mathrm{~g}$, respectively). furadon and castor oil had no statistically significant difference at a $P=0.05 \%$ level of significance. The then followed treatment was garlic extracts $1.26 \mathrm{~g}$ and then followed by ginger extracts $1.23 \mathrm{~g}$, while in check least dry root weight was observed $1.0 \mathrm{~g}$. All the treatments showed statistical significance over a check at a $P=0.05 \%$ level of significance, as shown in (Fig. 6).

We also recorded the total chlorophyll content, pre and post-application of treatments to the RKN-inoculated plants. In (Fig. 7) suggests that the RKN application harmed the total chlorophyll contents of the treated plants. 


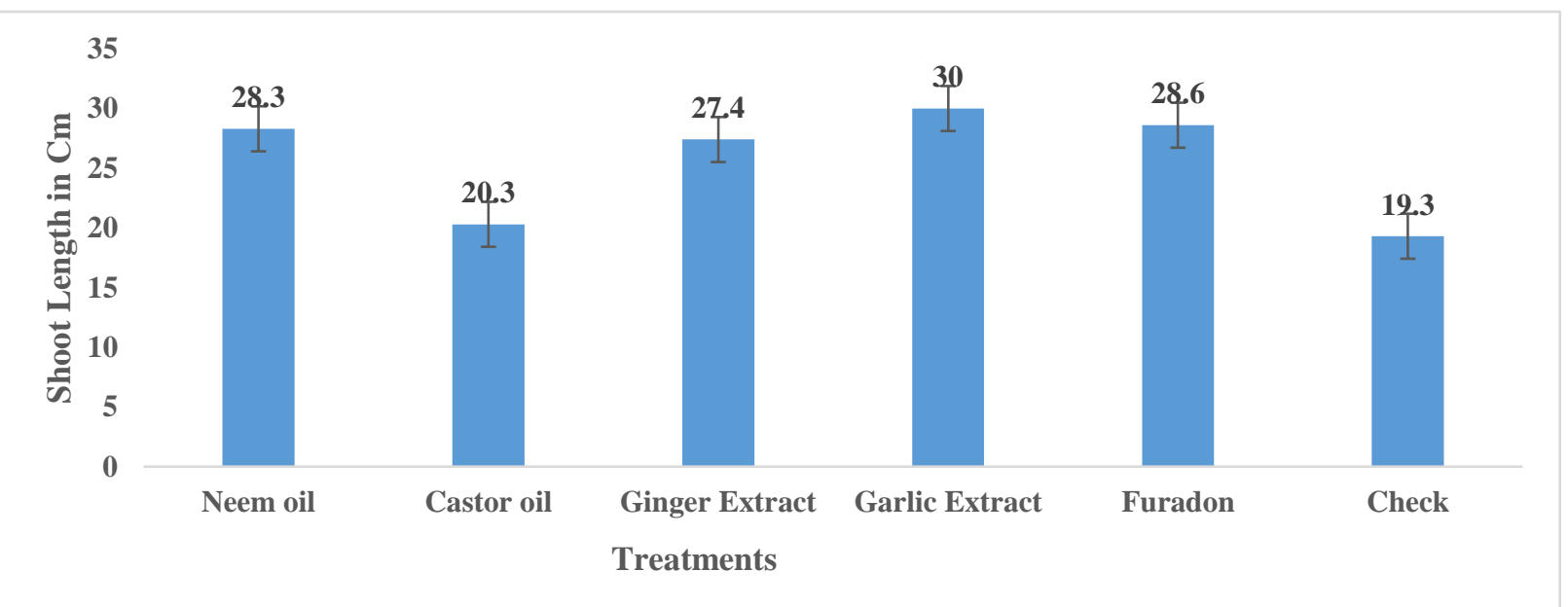

Figure 1. Shoot length after application of treatments to Sunflower root system inoculated with Meloidogyne incognita

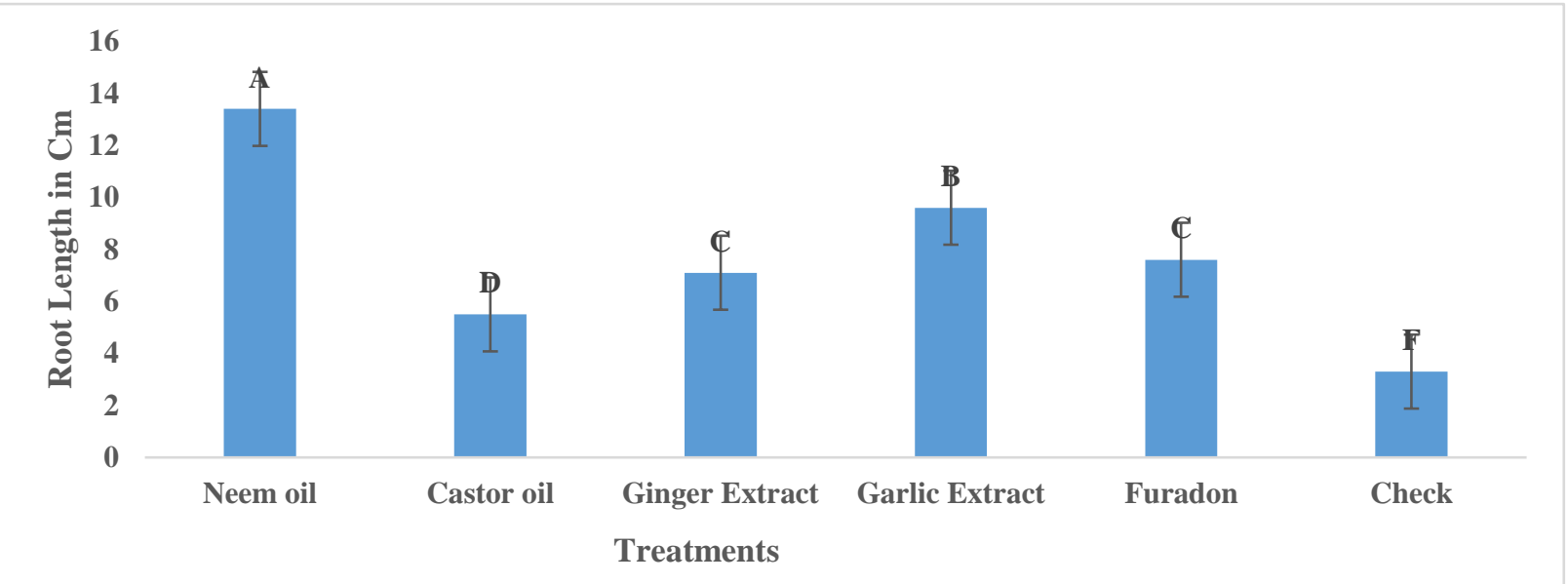

Figure 2. Root length after application of treatments to Sunflower root system inoculated with Meloidogyne incognita

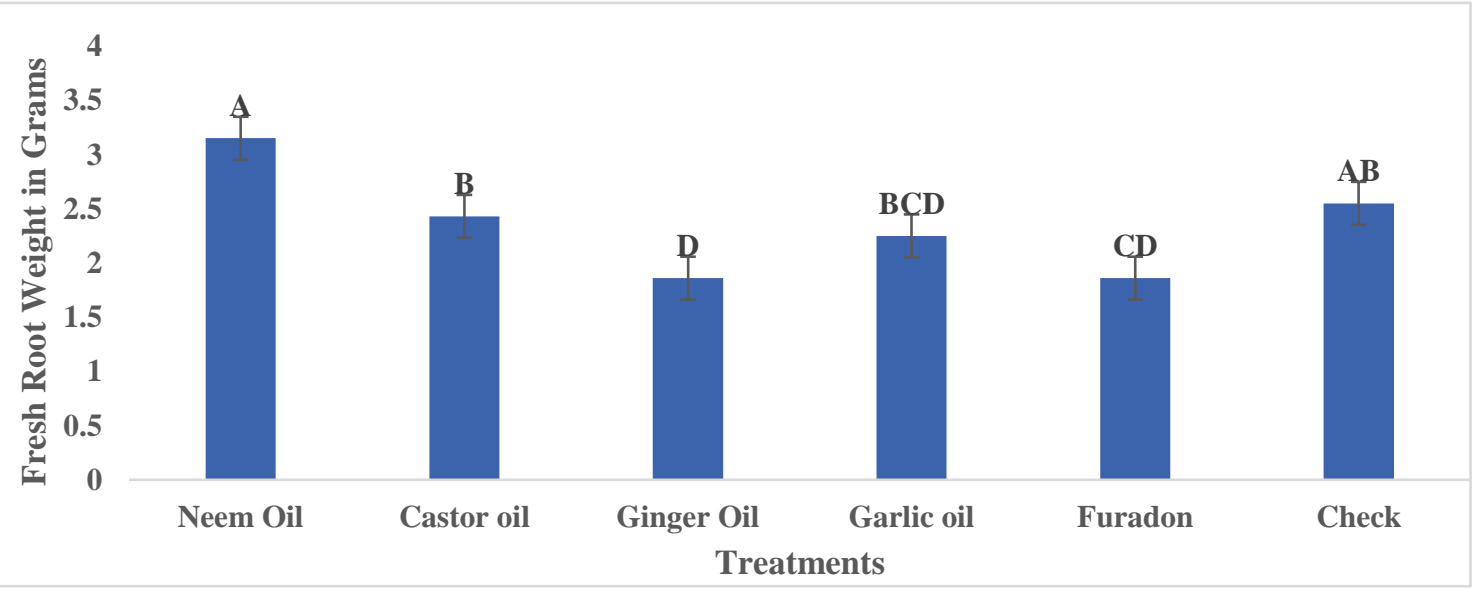

Figure 3. Fresh root weight after application of treatments to Sunflower root system inoculated with Meloidogyne incognita 


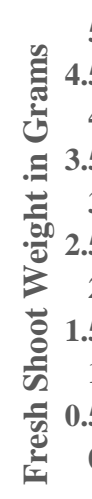

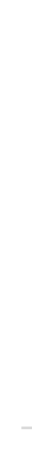
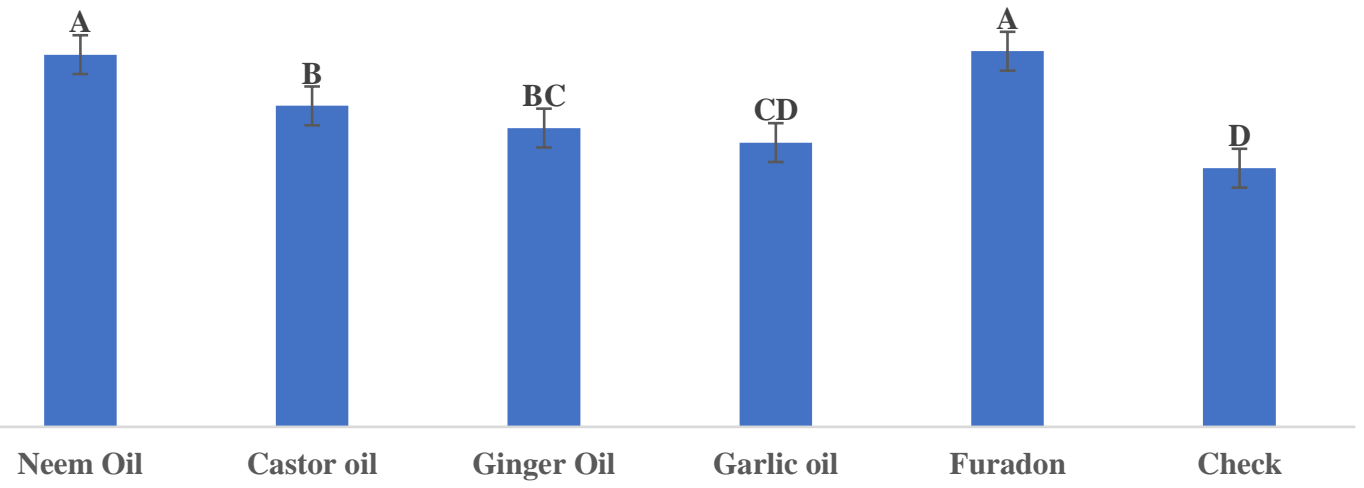

Treatments

Figure 4. Fresh shoot weight after application of treatments to Sunflower root system inoculated with Meloidogyne incognita

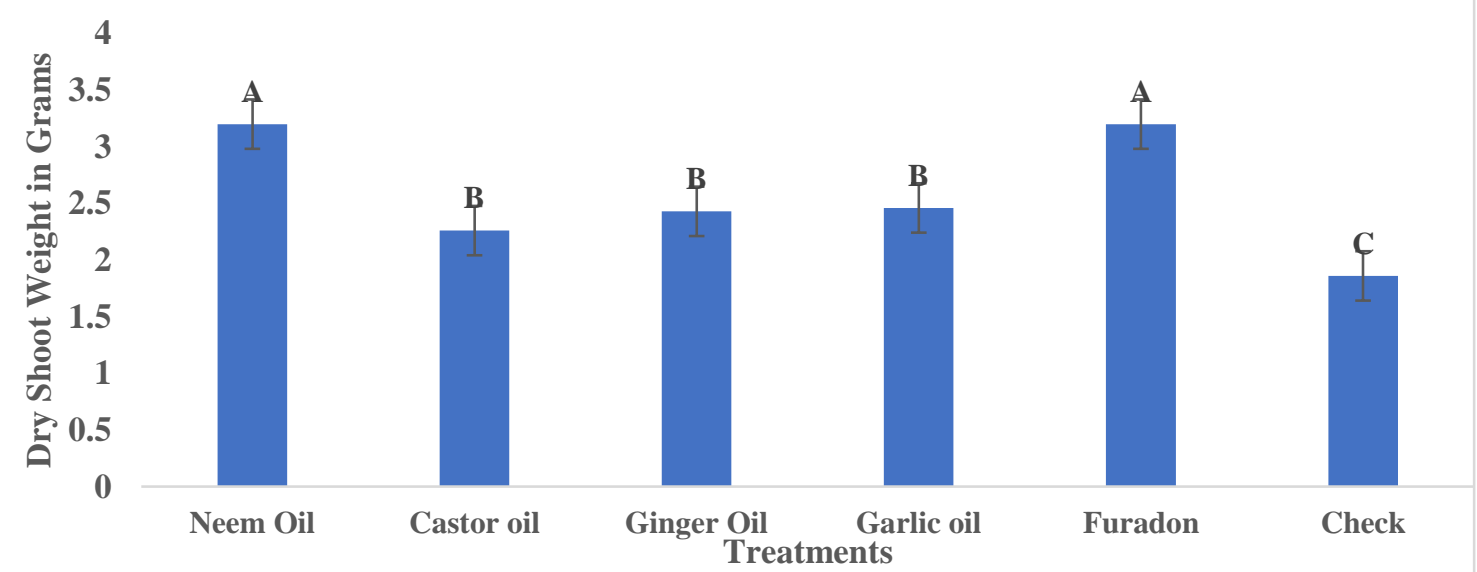

Figure 5. Dry shoot weight after application of treatments to Sunflower root system inoculated with Meloidogyne incognita

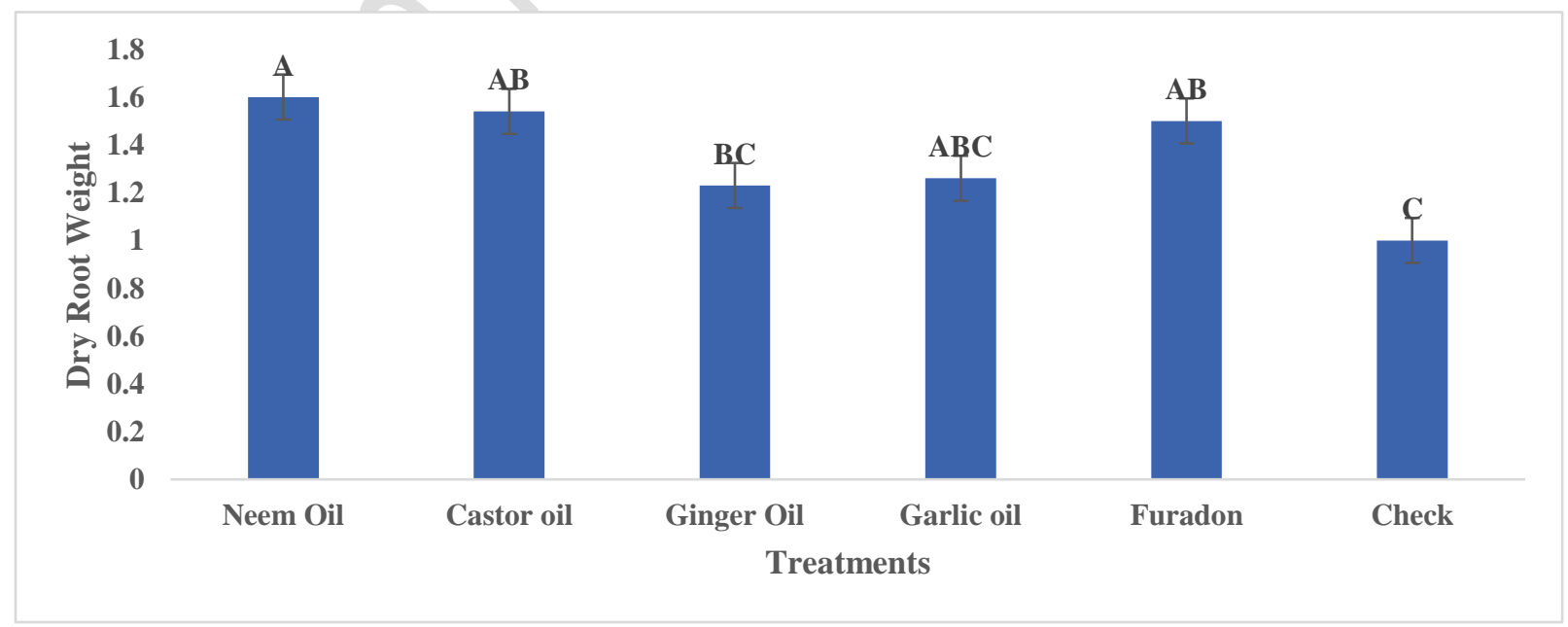

Figure 6. Dry root weight after application of treatments to Sunflower root system inoculated with Meloidogyne incognita 


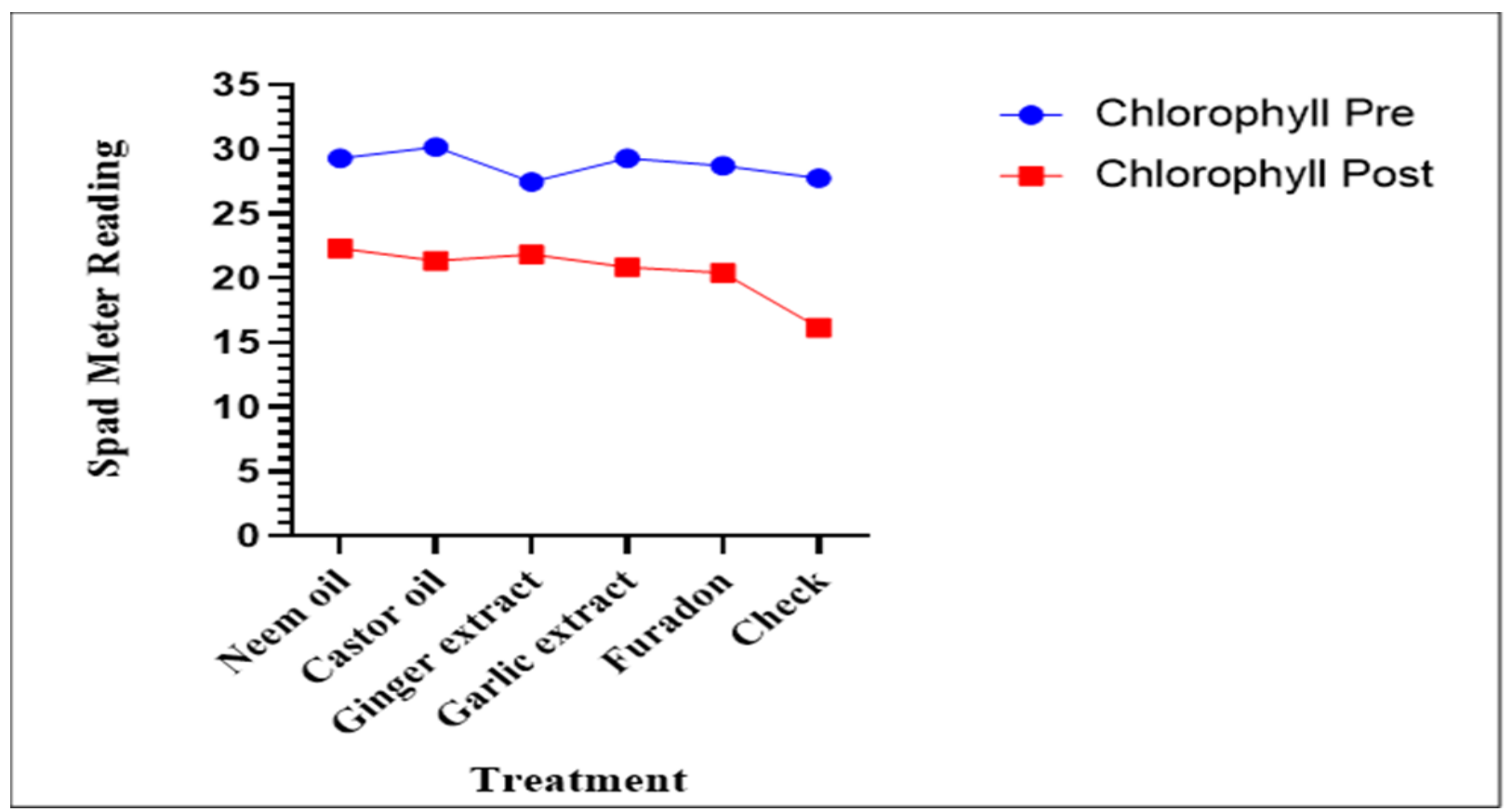

Figure 7. Pre and Post readings of SPAD meter after application of treatments to Sunflower root system inoculated with Meloidogyne incognita

\section{Discussion}

The Greenhouse experiment results indicate that neem oil significantly reduced the number of galls to 0.8 , lowered the number of egg masses (0.80), and a reduced number of $\mathrm{J} 2 \mathrm{~s}$ population (1.46). These results confirm the previous work of many researchers, including Sivakumar [18], Singh and Summaya [19]. Agriculturists are using neem oil formulation from ancient times for pest management practices [20]. The main toxic constituent found in neem is Azadirachtin. Resha and Rani [21] reported that aldehydes, fatty acids, amino acids, and phenols are the main compounds released, which are highly toxic to the nematode population. The improved plant growth parameters could be possibly be related to the presence of compounds like Azadirachtin, triterpenoid, limonoid, phenol, salannin, carotenoids, ketones and steroid which are accumulated in the infected plant cells and inhibit the growth activities of nematodes and thus, successively improve the plant growth [21].

Garlic extract successfully inhibited the nematode growth parameters. The total number of galls was 1.1, egg masses (1.0), and $\mathrm{J} 2 \mathrm{~s}$ population 2.0. Current performance of garlic extract revel that it was one of the best treatment applied in this experiment. The performance of garlic could be due to the presence of allicin, which has the potential of inhibiting the normal growth functioning of the nematode population. Our findings are parallel to the previous research work of Gupta and Sharma [22], they reported that garlic extract contains allicin, which possesses toxic properties to RKN. Masamha et al. [23] also reported the enhanced performance of garlic, and they suggested that garlic extract inhibits movement activates along with feeding and some other essential life functions, including reproduction.

The current results of the experiment revealed the nematicidal potential of ginger extract. As ginger extract successfully lowered the overall population of nematode and also improved the plant growth parameters. Several researchers reported the nematicidal activates of ginger like Singh et al. [24], Youssef et al. [25]. The possible explanation for the activities of the ginger extract could be due to the presence of secondary metabolites like saponins, alkaloids, flavonoids, phenols, terpenoids, and 
glycosides. The main active ingredient of ginger is gingerol. The improved plant growth parameters could be related to the presence of gingerol, which made the plant environment so unfavorable to the nematode population.

Castor oil initial response was instrumental; however, it is activity declined drastically as compared to other treatments. Our current results of castor oil differ from the previous work of Tibugari [26] as the castor oil showed a minimum effect on the population and galls reduction in roots. The current lower impact of castor oil on the overall population and galls formation is complete indifference with those of El-Nagdi et al. [27]. The performance of castor oil on RKN could be due to the lack of penetration into the cuticle of the RKN body. Castor oil lowered loss in effectiveness could also be due to the dilution with the irrigation or it naturally degraded.

Furadon was found very effective in controlling the nematode population, and it also improved the plant growth parameters. This effect could be associated with the dose used against RKN as many pesticides like fenthion, lambda-cyhalothrin, and deltamethrin fail to effectively kill the RKN in the roots because of the lower concentration used against RKN.

\section{Conclusion and recommendations}

In conclusion, the current results showed that plant-based compounds possess nematicidal properties. Using these phytochemicals gives a cheap and easy method of controlling nematodes. Neem oil has shown to be highly toxic against nematodes and had the potential to be used in Integrated Pest Management (IPM). Further studies are however needed to find out the exact action sites of these phytochemicals. The current result suggests the use of these plant as a tool for the management of these endophytic nematodes. We recommend from the current research that neem oil, garlic and ginger extracts should be used in nematode management programs.

\section{Authors' contributions}

Conceived and designed the experiments: $\mathrm{S}$ Ahmad, Performed the experiments: A Hameed, Nematode Extraction: AUR Saljoqi,
Analyzed the data: B Safia, Chemical Preperation: A Ali, Wrote the paper: S Ahmad. References

1. Shah NA, Shah H \& Akmal N (2005). Sunflower Area and Production Variability In Pakistan: Opportunities And Constraints. Helia 28: 165-178.

2. Mirza MS \& Beg A (1983). Diseases of Sunflower in Pakistan in 1982. Helia 6: 55-56.

3. Mukhtar I (2009). Sunflower disease and insect pests in Pakistan: A review. Afr Crop Sci J 17: 109-118.

4. Rehman A, Bibi R \& Hafeez-Ullah M (2006). Screening of different sunflower cultivars against root-knot nematode. JASS 2:182-184.

5. Trudgill DL, \& Blok VC (2001). Apomictic, polyphagous root-knot nematodes: exceptionally successful and damaging biotrophic root pathogens. Annu Rev Phytopathol 39: 53-77.

6. Mukhtar T, Arooj M, Ashfaq M \& Gulzar A (2017). Resistance evaluation and host status of selected green gram genotypes against Meloidogyne incognita. Crop Prot 92: 198-202.

7. Mukhtar T, Jabbar A, Raja MU \& Javed H (2018). Re-emergence of wheat seed gall nematode (Anguina tritici) in Punjab, Pakistan. Pak J Zool 50: 1195-1198.

8. Khattak B (2008). Biological management of root knot nematode Meloidogyne javanica (Treub) with Trichoderma harzianum Rifai in Tomato. Ph.D Thesis (Nematology), Department of Plant Pathology, NWFP, Agric Uni, Peshawar pp 157.

9. Shurtleff MC \& Averre CW (2000). Diagnosing plant diseases caused by nematodes. American Phytopathological Society (APS Press).

10. Williamson VM, \& Hussey RS (1996). Nematode pathogenesis and resistance in plants. Plant Cell 8: 1735-1745.

11. Rivoal R \& Cook R (1993). Nematode pests of cereals. In Plant parasitic nematodes in temperate agriculture, $\mathrm{p}$. 
259-303. Wallingford, UK, CAB International.

12. Chitwood. DJ (2002). Phytochemical based strategies for nematode control. Annu Rev Phytopathol 40: 221-249.

13. Pérez MP, Navas-Cortés JA, PascualVillalobos MJ \& Castillo P (2003). Nematicidal activity of essential oils and organic amendments from Asteraceae against root-knot nematodes. Plant Pathol 52: 395-401.

14. Naz I, Palomares-Rius JE, Blok V, Khan MR, Ali S \& Ali S (2013). In vitro and in planta nematicidal activity of Fumaria parviflora (Fumariaceae) against the southern root-knot nematode Meloidogyne incognita. Plant Pathol 62: 943-952.

15. Azam T, Hisamuddin \& Robab MI (2010). Effect of Initial Inoculation of Meloidogyne javanica on Growth and Yield of Lagenaria siceraria. Am J Sci 6: 617-622.

16. Naz I, Palomares-Rius JE, Khan SM, Ali S, Ahmad M, Ali A \& Khan A (2015). Control of Southern root knot nematode Meloidogyne incognita (Kofoid and White) Chitwood on tomato using green manure of Fumaria parviflora Lam (Fumariaceae). Crop Prot 67: 121-129.

17. Gomez KA \& Gomez, AA (1984). Statistical procedures for agricultural research. John Wiley \& Sons.

18. Sivakumar M \& Gunasekaran K (2011). Management of root knot nematodes in tomato, chilli and brinjal by neem oil formulations. J Bio Pest 4: 198-200.

19. Singh K \& Hali S (2017). Nematicidal Efficacy of Neem (Azadirachta indica, A. Juss) Seed Extract against Meloidogyne incognita. International Journal Of Plant \& Soil Science 18: 1-6.

20. Javed $\mathrm{N}$, Gowen SR, Inam-ul-Haq $\mathrm{M}$, Shainab F \& Pembroke B (2008). Efficacy of neem (Azadirachta indica) formulations on biology of root-knot nematodes (Meloidogyne javanica) on tomato Crop Prot 27: 36-43.

21. Resha S, \& Rani S (2015). Management of root knot nematode (Meloidogyne incognita) using neem (Azadiractha indica) J Environ Sci Toxicol Food 9: 1215.

22. Gupta R \& Sharmaj NK (1993). A study of the nematicidal activity of allicin an active principle in garlic, Allium sativum L., against root-knot nematode Meloidogyne incognita (Kofoid and White, 1919) Chitwood, 1949. Int J Pest Manag 39: 390-392.

23. Masamha B fadzirayi CT \& Mukutirwa I (2010). Efficacy of Allium sativum (Garlic) in Controlling Nematode Parasites in Sheep. Intern J Appl Res Vet Med 8: 161-169.

24. Singh R, Mehta A, Methta P \& Shukla K. 2011. Anthelminthic activity of rhizome extracts of Curcuma longa and Zingiber officinale (Zingiberaceae). Int J Pharm Sci 3: 236-237.

25. Youssef MMA, El-Nagdi WMA \& Dawood MG (2015) Population density of root knot nematode, Meloidogyne incognita infecting eggplant as affected by medicinal plant aqueous extracts. Appl Sci Report 10: 8-11.

26. Tibugari H, Mombeshora D, Mandumbu R, Karavina C \& Parwada C (2012). A comparison of the effectiveness of the aqueous extracts of garlic, castor beans and marigold in the bio control of rootknot nematode in tomato. IJAT 8: 479-492.

27. El-Nagdi WMAE \& Youssef MMA (2013). Comparative efficacy of garlic clove and castor seed aqueous extracts against the root-knot nematode, Meloidogyne incognita infecting tomato plants. J Plant Prot Res 53: 285-288. 